\title{
PALIPERIDONE INDUCED TARDIVE DYSKINESIA: CASE REPORTS
}

\author{
Niraj Ravani' ${ }^{1}$, Sanjay Jadhav ${ }^{2}$
}

\section{HOW TO CITE THIS ARTICLE:}

Niraj Ravani, Sanjay Jadhav. "Paliperidone Induced Tardive Dyskinesia: Case Reports". Journal of Evolution of Medical and Dental Sciences 2014; Vol. 3, Issue 54, October 20; Page: 12496-12498,

DOI: $10.14260 /$ jemds/2014/3653

ABSTRACT: Two cases of TD following treatment with Paliperidone are reported. Both patients were administered Paliperidone, for a very short period, following which they developed Tardive Dyskinesia. CONCLUSION: Second generation antipsychotics are traditionally believed to cause lesser tardive dyskinesia in particular. It seems the cases of tardive dyskinesia with second generation antipsychotics are underreported.

KEYWORDS: Paliperidone, Tardive Dyskinesia.

INTRODUCTION: Both conventional and atypical antipsychotics cause an up-regulation of dopamine2 receptors and have been associated with tardive dyskinesia. Studies of adult and elderly subjects have shown a greater incidence of tardive dyskinesia among patients who were administered conventional antipsychotic drugs than those given atypical antipsychotic drugs.(1) Second-generation antipsychotics conferred a lower risk for tardive dyskinesia at 6 months than first-generation antipsychotics.

In addition, patients with tardive dyskinesia at baseline who were receiving second generation antipsychotics were less likely than patients receiving first-generation antipsychotics to have tardive dyskinesia symptoms at 6 months. A sensitivity analysis suggested no bias related to pharmaceutical industry financial support (2).We, report two cases of Tardive Dyskinesia, following treatment with Paliperidone.

CASE REPORT 1: A 35 year old male was brought with complains of abnormal behavior in the form of abusive aggressive behavior, disinhibition in form of removing clothes and moving around naked in the house in front of his 7 year old daughter. He fulfilled the DSM IV criteria for Schizophrenia Undifferentiated type. Patient was started on Paliperidone, $3 \mathrm{mg}$ hs. He improved considerably with the treatment as reported by his wife. After around four months of treatment patient was found to have Tardive Dyskinesia. Other causes of orofacial dyskinesia were ruled out. Paliperidone was stopped. Patient showed improvement in his Tardive Dyskinesia.

CASE REPORT 2: A 49 year old female had come with complains of insomnia and sadness. The reason for her insomnia and sadness was suspiciousness on her husband since last six months. She fulfilled the DSM IV criteria for Delusional Disorder. She was started on olanzepine and Fluoxetione following which she improved.

On follow up her lipid profile was found to be elevated and hence Olanzepine was discontinued. She was started on Paliperidone $3 \mathrm{mg}$ which was gradually increased to $6 \mathrm{mg}$. After two months of treatment she developed Tardive Dyskinesia. Other causes of orofacial dyskinesia were ruled out. Paliperidone was stopped. Patient showed improvement in her Tardive Dyskinesia. 
DISCUSSION: There are various studies which say that, Tardive dyskinesia incidence was higher with second-generation antipsychotics than previously reported, possibly due to recent studies with relatively short mean durations and use of nonstandard tardive dyskinesia definitions.(3)

The incidence of tardive dyskinesia with recent exposure to atypical antipsychotics alone was more similar to that for conventional antipsychotics than in most previous studies. Despite high penetration of atypical antipsychotics into clinical practice, the incidence and prevalence of tardive dyskinesia appeared relatively unchanged since the 1980s. Clinicians should continue to monitor for tardive dyskinesia, and researchers should continue to pursue efforts to treat or prevent it.(4)

Results from 11 long-term studies support the idea that second-generation antipsychotics have a reduced risk for tardive dyskinesia, compared to first-generation antipsychotics, although the doses of haloperidol used in the comparator studies were relatively high. More carefully designed studies, ideally lasting beyond 1 year and comparing the effects of different second-generation antipsychotics in patients who have never taken first-generation antipsychotics, are needed to estimate the true risk. It would not appear premature for clinicians to consider these findings in making long-term treatment decisions. ${ }^{(5)}$

CONCLUSION: Second generation antipsychotics are traditionally believed to cause lesser extra pyramidal symptoms and lesser tardive dyskinesia in particular. There are several studies to support this. But, it seems the cases of tardive dyskinesia with second generation antipsychotics are underreported.

\section{BIBLIOGRAPHY:}

1. Kane JM. Tardive dyskinesia rates with atypical antipsychotics in adults: prevalence and incidence. J. Clinical Psychiatry 2004; 65 Suppl 9:16-20.

2. Tenback DE, van Harten PN, Slooff CJ, Belger MA, van Os J; SOHO Study Group. Effects of antipsychotic treatment on tardive dyskinesia: a 6-month evaluation of patients from the European Schizophrenia Outpatient Health Outcomes (SOHO) Study, J. Clinical Psychiatry, 2005 Sep; 66 (9):1130-3.

3. Correll CU, Schenk EM, Tardive dyskinesia and new antipsychotics. Curr. Opine Psychiatry, 2008 Mar; 21 (2):151-6.

4. Woods SW, Morgenstern H, Saksa JR, Walsh BC, Sullivan MC, Money R, Hawkins KA, Gueorguieva RV, Glazer WM. Incidence of tardive dyskinesia with atypical versus conventional antipsychotic medications: a prospective cohort study, J. Clin Psychaitry, 2010 Apr; 71(4):46374.

5. Correll CU, Leucht S, Kane JM.Lower risk for tardive dyskinesia associated with secondgeneration antipsychotics: a systematic review of 1-year studies. A.J. P, 2004 Mar; 161 (3): 414-25. 


\section{CASE REPORT}

\section{AUTHORS:}

1. Niraj Ravani

2. Sanjay Jadhav

\section{PARTICULARS OF CONTRIBUTORS:}

1. Professor and HOD, Department of Psychiatry, Terna Medical College, Nerul, Navi Mumbai.

2. Associate Professor, Department of Psychiatry, Terna Medical College, Nerul, Navi, Mumbai.

\section{NAME ADDRESS EMAIL ID OF THE} CORRESPONDING AUTHOR:

Dr. Niraj Ravani,

\#702, Locxon Tower,

Plot 4A, Sector 14,

Nerul, Navi Mumbai-400706.

Email:nirajrav@yahoo.com

Date of Submission: 25/09/2014.

Date of Peer Review: 26/09/2014.

Date of Acceptance: 15/10/2014.

Date of Publishing: 18/10/2014. 